\title{
NEED FOR REGULATORY AFFAIRS PERSONNEL DEVELOPMENT
}

\section{Dear Reader,}

Scientists seldom try to read regulations, let alone understand or interpret them. Most pharmacy students would have studied a subject called Forensic Pharmacy and read the almost bible like book by late Prof. B M Mittal with the same title. Late Mr. KattiShettar, the then Drugs Controller of Karnataka taught me this subject. He used to bring printed cartons, labels, literature while teaching Drugs and Cosmetics Act and Rules in 1970-71. He used to tell me "what kind of research scientist would you become if you don't know regulations?"

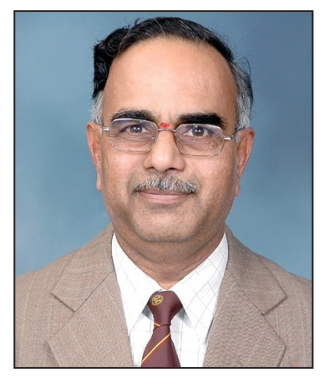

Pharmaceuticals are highly regulated worldwide with great clarity on scientific and technical information and data on the drug, premises, equipment, process and personnel involved in the manufacture and the total supply chain till it reaches the patients are regulated. A fairly large amount of documentation is required before any drug is approved for marketing and even imported to a country. It is a known fact that elaborate guidelines and documentation are demanded, inspection and audit of all stages are carried out in this process. This led to development of a new category of scientists whose main expertise was understanding the regulatory requirements and preparing adequate documentation with detail and accuracy. Such personnel got the title of regulatory affairs scientists (RAS).

$R A S$ became the bridge between the R\&D department, manufacturing, quality assurance wings and the business heads. Primarily RAS had to deliver timely obtaining approvals from regulators to support marketing and business needs. Delays meant financial and business loss. These experts with skills of reading the law, regulations, guidelines, are responsible to translate them to implementable processes and procedures, specifications along with data on validations through well planned testing and appropriate documentation. Many Indian pharmaceutical firms suffered to receive deficiency notes from global regulators. Inadequate documentation were primary reasons while quality produced was never a question.

Health care is moving from an illness centric to a wellness centric approach. In addition to medicines, foods, medical foods, supplements and nutraceuticals and dermatologicals are expanding the health care routes. This has led to need for understanding regulations related to foods, food additives, labelling, advertisements, nutrition and health benefits, claims that can be made and those claims that are not permitted. Unlike drugs where the claims are approved while issuing the marketing authorization, in the foods and supplements area health claims are not permitted automatically. The 'risk reduction and health benefits claims' have to go through a separate regulatory approval process.

The expanding health care in India and greater consumer appeal has opened the area of Ayurveda based products and herbal remedies. Products made with botanicals can be fitted into Ayurvedicmedicines category on one side and phytopharmaceuticals as drugs a category on the other with clear regulations in place.

Hence the role of RAS is expanding from medicines to foods to supplements / nutraceuticals, to Ayurvedic medicines and phytopharmaceuticals depending on the business objectives of the 
firms. Reduced number of NCEs, reduced generic drug introduction possibilities, difficulties and demands to introduce new fixed dose combinations, many pharma companies are looking at other categories of health care products.

In this scenario employment opportunities for RAS is increasing. However, trained and qualified RAS are not available. Most RAS are not treated on par with other scientists and some of them feel they are doing a clerical job which is not true.

More than ever, innovative research, Intellectual Property Rights (IPR) practice and protection of IPR and the consequent need for detecting patentability or non-infringing operations are calling for alertness and attention of the Regulatory Affairs Scientists. Working around solutions and serendipitous inventive opportunities from deviation analysis can be achieved by RAS only through basic understanding of IPR regulations and practices. As such IPR is also forming an essential aspect and integral part of RAS training.

It may be appropriate for pharmaceutical education institutions and universities to initiate appropriate courses to convert a scientist to a regulatory affairs scientist. A six months to one year course to begin with may be adequate for a postgraduate in pharmacy, food science or Ayurveda to become fully functional RAS. Professional associations can also conduct such regulatory affairs courses on a part time basis or online courses with a specified number of contact hours in a R\&D or factory.

Dr D B Anantha Narayana

Bengaluru

(with inputs from Editor in Chief, Indian Drugs)

https://doi.org/10.53879/id.57.09.p0005

\section{About The Guest Editor}

Dr. Anantha Narayana, is the Chief Scientific Officer, AYURVIDYE TRUST, Bangalore. He Championed the Notifications of Supplements and Nutraceuticals Regulations, FSSAI, 2016 Updated in 2017 and Phytopharmaceuticals as Drugs under Drugs \& Cosmetics Act \& rules, 2016. He is a recipient of Indian Drugs award for Contribution to IDMA and Indian Drugs and is a recipient of Eminent Pharmacist's Award of IPA, 2007. Currently is an expert member, amongst others contributing significantly to 1) Member-Expert committee - NonSpecified Foods \& Food Ingredients - FSSAI, 2) Chairman-Expert Committee-Advertisement \& Claims - FSSAI, 3) Chairman-Scientific Panel - Nutraceuticals of FSSAI. 4) Chairman - Phytopharmaceuticals \& Herbal products of Indian Pharmacopeia Commission 5) Member-Steering Committee of NMPB, Ministry of Ayush.

He continues to guide youngsters in research and also guides many startup firms in the area of Supplements/ Nutraceuticals, Foods, herbals and cosmetics.

$\square$

If you would like to comment on the editorial please write to us at publications@idmaindia.com 